\title{
Research on Development Strategy of Industrial Transformation and Upgrading Demonstration Base in Guangdong-Hong Kong- Macao Greater Bay Area-- A Case Study of Xintai Group "Gold Town"
}

\author{
Luo Lisheng \\ Guangdong University of Science and Technology, Dongguan, Guangdong 523083, China
}

\begin{abstract}
A "Gold town" is a characteristic town featuring gold industry and being operated by leading enterprises. Xintai Group in gold and jewelry industry has launched a "Gold Town" project in Houjie, Dongguan, Guangdong by taking advantage of its own capital and technology, seizing the opportunity of gold and jewelry industry transformation and gathering the strength of traditional gold and jewelry industry in Houjie. "Gold Town" is a key project supported by the local government in response to the national call. When setting up this project, Xintai Group introduced the characteristic development concept of European towns and optimized its own industrial structure, and meanwhile it aimed to build an industrial ecological base of gold and jewelry town and aggregate industrial development resources. This project has been partially completed and the first phase has been transferred to the production and operation stage. Therefore, it is of great significance for both Xintai Group and the local government to explore the appropriate development strategy of the "Gold Town" project.
\end{abstract}

\section{Introduction}

Currently, with the rapid and steady development of China's economy, the national income continues to rise and residents' consumption structure has been continuously upgraded. The new consumption form of "visiting small towns, buying new products and gaining new experiences" has generated a number of new urbanization projects integrating consumption industry, tourist attractions and new urbanization development. As one of the most important cities in Guangdong province, Dongguan has a long development history of gold industry. Since the 1970s, the gold industry in Houjie has been famous for its exquisite workmanship and its high quality. Meanwhile, thanks to the "Tourism Service Plus Industrial Transfer", Dongguan has been committed to promoting the transformation and upgrading of the service industry in recent years, simultaneously boosting the development of advanced manufacturing industry and strategic emerging industry. By making full use of the historical opportunity of GuangDong's first-step development, Xintai Group has deepened its supply-side reform while taking the industrial chain integration as its goal. It has also customized a comprehensive industrial project for Houjie, namely "Gold Town", which has integrated the existing and scattered resources of gold industry and emphasized the connotation of gold culture and partial community function.
At present, the fundamental construction of the project has been partially completed and the project has been transferred to the stage of production and operation. Under the new situation of the post-epidemic period, Xintai Group has gained guidance for the future development of "Gold town" from development opportunities such as "Shenzhen first demonstration area of socialism with Chinese characteristics ", "Guangdong, HK \& Macau big bay", "Guangdong industrial transformation and upgrading", through in-depth research of Xintai Group's "Gold town" development strategy.

\section{Significance of the research on the development strategy of "Gold Town"}

Combined with the present conditions of Dongguan city, the research on the development strategy of "Gold Town" is based on what other scholars at home and abroad have achieved in this field. The research also needs to reference the Dongguan Modern Industry System for Medium and Long-term Planning Outline (2020-2035) so as to further study "Gold Town" which is one of the top ten key transformation and upgrading industries in Dongguan. 


\section{Advantages of the "Gold Town" project}

1. Excellent geographical location. Located in the Pearl River Delta Gold Corridor, the Gold Town in Binhai New Area enjoys a good economic environment. With the rapid economic development of the Pearl River Delta region, Dongguan is close to Guangzhou in the north, Shenzhen in the south and Hong Kong in the back. Thousands of foreign enterprises and more than 30,000 private enterprises gather in Dongguan with a sound foundation and a great strength of the traditional industry. It can be observed from the satellite map that the Gold Town is surrounded by green land and adjacent to a number of parks and scenic areas, showing a cutting edge of a beautiful environment. "Gold Town" is located in the most prosperous commercial center of Houjie town, adjacent to the government center, with mature surrounding supporting facilities. Its northwest side is connected to the Liaoxia Station of Dongguan Metro Line 2 , from which it can directly benefit the convenience of rail transit and passenger flows.

2. Market diversification. The Gold Town has long been known for its diversified operations. Based on the integration of the whole industry chain of gold and jewelry, the project covers intelligent industrial buildings etc., providing habitats and development space for various types of enterprises in the industry.

3. Rich industry resources. The Gold Town has successfully introduced a number of well-known leading enterprises of gold and jewelry, such as Laofengxiang, Jinyi Culture, Shengfeng Head Jewelry, Jiayan Pearl Jewelry, etc.

4. Resource sharing. "Gold Town" has adopted the development mode of "Industry plus Finance" to build a special town with the theme of gold and jewelry cultural experience and in combination of industry and finance as its foundation. In recent years, the local government has been trying to integrate the whole industrial chain of the gold and jewelry industry to create a new platform that combines cultural tourism, trade, exhibition and sales, etc.

5. In line with the direction of industrial structure transformation of Dongguan. Dongguan government has defined it as an industrial transformation and upgrading project. The project is processed according to the Recognition and Management of Dongguan's Industrial Transformation and Upgrading Base. It is also the reply of Dongguan government office to 'Gold and Jewelry Production and Supporting Project in Dongguan, Guandong (phase I)' and recognized as the city industry transformation and upgrading base (east government office reply [2018] no. 78).

6. Good industrial foundation. Firstly, there are scattered enterprises of gold and jewelry industry in Houjie District of Dongguan City, which had a good industrial development atmosphere and mature supporting facilities. Secondly, the gold industry of Houjie is widely recognized in Dongguan City and even Guangdong Province, which is easy to generate corresponding brand association. Thirdly, Xintai Group has good technology and experience accumulation.

\section{Opportunities for the "Gold Town" project}

1. Abroad industrial prospects.

2. National policy encouragement. China has introduced a series of preferential policies for private enterprises at the Third Plenary Session of the 18th CPC Central Committee, which vigorously supported private enterprises. It has made efforts to establish a stable order in the gold and jewelry market, and to put an end to all kinds of possible violations, which will certainly bring new development opportunities to the gold and jewelry industry. In addition, as "Gold Town" is the major project of Dongguan municipal government, all settled enterprises will enjoy industrial support policies in taxation, financing and other aspects.

3. Diversified consumer demand. With continuous improvement of social and economic development, the purchasing power of consumers is also increasing.

4. The market segment has not been deeply developed. Traditional and large gold and jewelry stores are no longer the mainstream, which are replaced by the more refined ones. The refinement of gold and jewelry has become an inevitable trend.

5. New momentum has been injected with the development of the Guangdong-Hong Kong-Macao Greater Bay Area. The structural upgrading of major cities in the Bay Area focuses on different aspects. Guangzhou and Shenzhen, two super cities, can rely on their advantages in trade, commerce, scientific and technological innovation respectively to increase the proportion of the service industry. Currently, Shenzhen focuses more on financial services and scientific and technological innovation to strengthen the headquarter economy and Dongguan's manufacturing industry.

\section{Guiding ideology of the development strategy of "Gold Town}

"Gold Town" is built in accordance with innovation, coordination, and green, open and shared development. It is a development platform with clear industrial positioning, scientific and technological elements, cultural connotation, ecological characteristics, (industrial) tourism business format and partial community functions. As a key project of transformation and upgrading of traditional industries in Dongguan city, Xintai Group's "Gold town" project aims to build a famous town with Dongguan characteristics and to drive the development of its all regions. To reach this goal, the "the Guiding Ideology Strategic Development of the Gold Town in Dongguan" needs to be carried out as well as "Layout Plan for Large Bay Area of Guangdong". Only in this way can the Gold Town be built into the most distinctive "Star Town of Dongguan". 


\section{Strategic goals of the development of "Gold Town"}

\subsection{To create a new and intelligent manufacturing industrial community and help enterprises transform and upgrade}

Intelligent manufacturing in Dongguan has stepped forward to the era of intelligent industry 4.0. The industrial park is not only a processing and production space, but also a modern comprehensive industrial community gathering its own research and development as well as the upstream and downstream resources. Industrial community is based on industry, but has the dual attributes of "industry" and "community". Not only does it have more space, but also it pays more attention to the establishment of industrial chain and the formation of industrial ecology. Thus, the industrial community can further stimulate the innovation and development of the industry, help to give full play to the synergistic effect and aggregation effect of the industry, and promote the sound development of the industrial cluster. The project of "Gold Town" should also step into the intelligent era of Industry 4.0 at the same time so as to build up a comprehensive industrial community with a whole industrial chain.

\subsection{To build industrial tourism area and establish a good corporate brand image}

Theme Blocks of gold and jewelry are featuring factory experience shops of manufacturing enterprises in the industrial park, allowing consumers to visit the whole production process of gold and jewelry products to get a good experience. In this way, the brand image can be established and the positioning of industrial tourism can be completed. Besides, industrial tourism can serve as one of the functions of the Gold Town. At present, the construction of Zone A of the first phase of "Gold Town" has been completed, and a number of excellent brands such as famous enterprises Laofengxiang, Xinbao Jewelry and Braun Jewelry have entered the park. In the future, the Gold Town will become a win-win ecosystem for more than 500 enterprises, eventually forming a whole industrial chain platform which combines gold jewelry equipment, production and processing, trade, exhibition and marketing, culture and tourism.

\section{Strategic Priorities of the Development of "Gold Town"}

\subsection{Inspire and cultivate the market}

In order to help the long-term development of the "Gold Town" project, it is far from enough to rely only on Xintai Group itself and the original enterprises of "Gold Town". What Xintai Group needs to do is to strengthen publicity and communication on the premise of guaranteeing its original basic conditions in order to guide other local or non-local enterprises and businesses to enter the "Gold
Town". More enterprises and businesses are conducive to expanding the scale of "Gold Town". A larger scale means higher visibility and stronger customer attraction, and it is also beneficial to developing external channels.

The target customer groups of "Gold Town" should not only be limited to the local city of Dongguan, but also open sales and publicity channels to sell its products to the whole country and even overseas. At the same time, close attention should be paid to national policies and strategic investment hot spots. It is also important to focus on countries and regions with high demand for gold and jewelry products and to be ready to open up new markets and develop new channels.

\subsection{Strengthen the industrial chain}

In view of the absence of the gold industry chain, it is essential to focus on attracting enterprises and merchants who can fill in the missing part in the investment attraction of "Gold Town", and to integrate the industrial chain to form a complete upper, middle and downstream industrial chain. More importantly, launch more and better jewelry processing products based on the complete industrial chain, and meanwhile, use the complete industrial chain to attract more potential tourists that are unknown to this project to visit and consume.

Besides, encourage its superior enterprises to merge with others in more related industries, such as logistics enterprises, and master the export transport channels of gold and jewelry by themselves. Forming stronger industry competitiveness through merger and acquisition is also helpful to improve the industrial chain. At the same time, encourage and guide related enterprises to carry out industrial transformation around the whole project and the industrial chain of "Gold Town", and remind enterprises and businesses of making full preparations to enter the Gold Town, to pay attention to misplaced development and to avoid overlapping and competitive development as well as homogenized development in time.

\subsection{Strengthen scientific and technological support}

The research strength of local relevant enterprises is not strong and there are many difficulties in independent research and development. Xintai Group should focus on the companies that are able to research and develop independently while carrying out various forms and channels of manufacture-learning-research cooperation, and striving to master relevant advanced technology of gold industry from upstream to downstream, which can help to keep unique and competitive advantages in the complex competition among enterprises.

Meanwhile, it is of importance to vigorously promote its own superior technology and to form a self-led industrial standard and even a higher-level standard system as soon as possible. 


\subsection{Introduce and cultivate professional talents}

The project of "Gold Town" not only covers gold industry, but also integrates tourism, service industry, manufacturing, internet and other industries, so the demand for talents is particularly large. Therefore, various policies and plans for introducing talents from provincial and municipal cities should be fully utilized to guide senior talents to flow into the Gold Town, and to make contributions to related projects and industries. In the mean time, a series of training activities should be carried out to improve the technical skills of professional and technical personnel, to update the management ideas of management personnel, and to improve the service attitude and enthusiasm of service personnel. Additionally, the Gold Town should be designed to establish an industrialization base by relying on its own advantages, to promote close cooperation with relevant universities, to set up a related training base led by Xintai Group, to explore a new apprenticeship system, and to train a batch of technical management and service personnel.

\section{Research and development strategy of "Gold Town"}

Based on the transformation and upgrading of the gold and jewelry industry, the "Gold Town" project is an integrated platform of the whole industry chain combining lean manufacturing, research and development design, exhibition and trade, and brand incubation. In terms of development strategy, the Gold Town endeavors to creatively build an industrial and financial platform, a research institute with new materials, an industrial service center, a R\&D and design center and other service windows to constantly improve the intelligent manufacturing technology and industrial innovation in gold and jewelry industry.

\subsection{Smart jewelry}

Smart jewelry, namely "Smart Technology plus Jewelry", is different from traditional jewelry. It integrates modern and latest technology and provides customers with diversified smart gold jewelry experience by using software applications, professional customized APP and Internet of Things. At present, smart jewelry has gradually attracted the attention of the industry and shown great market potential.

The Gold Town effectively integrates the resources of the gold and jewelry industry, comprehensively connects the upstream and downstream of the gold and jewelry industry, and set up a development platform for the whole industry chain. As a new force in the jewelry industry ecology, smart jewelry will become a new highlight in the innovation and development of the gold and jewelry industry.

\subsection{Automatic touch welding machine}

Science and technology are the first productive forces, and research and development have an important impact on product innovation and core competitiveness of enterprises. The Gold Town has attached great importance to product research and development as well as technological innovation since its inception and it has been committed to the continuous improvement of gold technology and industrial innovation.

As the saying goes, "Who has mastered the core technology, who will have the confidence to win". The product competition of the enterprise lies not only in the quality, but also in the innovation and gold content of the product. Good products need good technology and good intelligent manufacturing equipment. In order to improve the gold intelligent manufacturing technology, the Gold Town has strengthened its scientific research while carrying forward the spirit of craftsmanship by relying on the R\&D and design center and the industrial service center. A good example is that it has developed the "automatic welding machine" with independent intellectual property rights to guarantee the quality, quantity and competitiveness of products.

\subsection{D printers}

We should mainly rely on ourselves to improve core technologies and cultivate absolute technological advantages. Strengthening technical cooperation, introducing new technologies and sharing scientific research results have become an important means to improve the technical level of processing gold in the Gold Town. Integration of resources and complementary advantages is also an important way to improve the technical level of processing gold in the Gold Town.

"3D printers" has been introduced to the Gold Town and more models of "3D printers" have been developed through continuous technical innovation in production practice, which makes it become one of the few domestic gold enterprises with intelligent printing technology. "3D printers" have also been widely used in many of the Gold Town's partners in gold jewelry industry. This has truly achieved a new situation where "Gold Town" controls the leading 3D printing technology, and plays an important role in gold technology and industrial innovation.

\subsection{MIC Culture and Art Center}

MIC Culture and Art Center is committed to promoting the development of the industry with creativity, and building a platform for young designers to realize their creative value by means of walking with teachers, discovering creativity, encouraging entrepreneurship, encouraging innovation etc.

MIC Creative Masters Competition, namely the International Jewelry Design Competition, is held by MIC Culture and Art Center, which provides a platform for creative exchange and a window on exhibition of works for international gold and jewelry designers. This can greatly enhance the innovation of the gold and jewelry industry. 


\subsection{Production and education integration, science and technology education}

In order to improve gold technology and industrial innovation, and promote scientific and technological innovation, the Gold Town and universities have jointly established industry-university research cooperation base, and mutually carried out the project of "production and education integration, science and technology education", which has given full play to its own advantages in production practice conditions and universities' advantages in technology, human resources and other resources to achieve win-win cooperation.

The cooperation projects of "integration of industry and education, science and technology education", include academic exchange, scientific research cooperation, professional talents co-cultivation, textbook development and course design, practice and training, employment, culture, innovation and entrepreneurship etc.

Although today's gold and jewelry market has a broad prospect, the technical threshold of the industry is not difficult to cross. In order to ensure the competitiveness of its gold and jewelry products in the market, the "Gold Town" project must pay attention to product technological innovation and industrial technological leadership. Only when we are able to take the lead in the overall technical level, can we occupy a prominent position in the gold and jewelry market for a long time.

\section{9 "Gold Town" Public Relations Strategy}

The public relation strategy refers to long-term and overall plans and countermeasures of the enterprise, centering on the core of public relations, taking the future as the orientation, so as to realize the overall goal of the enterprise public relations. It has five characteristics of integration, directionality, long length of time, risk and hierachy. The strategic operation of public relations is to unify the thinking and consciousness, to focus on the overall situation, to start from the details, and to do forward-looking and promising work in a planned and targeted way.

Public relations activities require enterprises to have a sense of public relations and whole staff participation. As the personal image represents the corporate image, every employee is the spokesperson for it. Creating a good social image is the basis for the survival and development of "Gold Town". When it comes to corporate visualization, the Gold Town should first train its employees to raise their awareness of improving the corporate image and strengthen the management of it in all directions. It's not a matter of a day, and not a person's business to create a good corporate image. We should strive to build an efficient and unified "Gold Town" with its own culture and spirit and enhance the core competitiveness of "Gold Town".

In a word, the project of "Gold Town" is still in the development stage, in which the relevant experience is not perfect and there are still shortcomings to overcome by specific measures. Thus, further research is required. But we are sure that through solving related problems, Xintai Group "Gold Town" can achieve strategic management more quickly and efficiently to fully display the development advantages and strengths of its gold industry characteristics.

\section{Acknowledgement}

1. Research on New Retail Business Model, "IndustryUniversity Cooperative Education Project", 2018, Ministry of Education (Project No.: 201802144007)

2. The Reform and Practice of the Course System of Applied Statistics in the Era of Big Data ", IndustryUniversity Cooperative Education Project", 2018, Ministry of Education (Project No.: 201802144005)

3. Guangdong University of Science and Technology, 2018 "Quality Engineering Project", "Guangdong University of Science and Technology -- Shenzhen Changheshanda E-commerce Co., Ltd. "Off-campus Practice Teaching Base of E-commerce major " (Project No.: CQ2018011)

4. Annual Scientific Research Project (Humanities and Social Science) of Guangdong University of Science and Technology in 2020, "Research on the Development Strategy of Dongguan" Gold Town" (Project No.: GKY2020KYBW-19)

\section{About the author:}

Luo Lisheng, male, Master of Business Administration (MBA), is a member of the Communist Party of China from Hubei province, taking charge of universityenterprise cooperation in Guangdong University of Science and Technology, and serving as senior human resource manager, senior financial planner, business management lecturer, e-commerce teacher, SYB entrepreneurship training lecturer.

Research Directions: Public Relations, Organizational Behavior and Human Resource Management, Organizational Strategy and Risk Management, Smart New Retail, College Students' Innovation and Entrepreneurship

\section{Reference}

1. Michael Porter. Competitive Strategy. CITIC Publishing House, 2014

2. Tang Gang. Characteristic Industries Development and Realization of New Urbanization - Study of Theoretical Mechanism and Economic Effect of "Characteristic Town" Model [J]. Business Research,2019(06):73-80.

3. ZENG J, CI F. Construction of characteristic towns under the background of new urbanization. Macroeconomic Management, 2016(12):51-56.]

4. Pei Hong. The adjustment of "high quality" of gold industry baton [N]. China Gold News,2019-1112(004). 